\title{
EJACULATORY REFLEX AND LUTEAL ACTIVITY INDUCTION IN MUS MUSCULUS
}

\author{
T. E. MaGILL ANd R. C. COUGHLIN* \\ Department of Psychology, Williams College, Williamstown, \\ Massachusetts 01267, U.S.A.
}

(Received 11th December 1968)

\begin{abstract}
Summary. Male mice were forcibly removed from oestrous females at times ranging from 1 to $7 \mathrm{sec}$ following the beginning of the ejaculatory reflex. Females were then tested to determine if luteal activity had been induced. The results indicate that the stimulus inducing luteal activity in the female is initiated 3 or $4 \mathrm{sec}$ after the beginning of the ejaculatory reflex. Observations of the penis during this reflex revealed a large increase in the diameter of the erect organ, particularly at the distal end. This anatomical change continued for 5 to $12 \mathrm{sec}$. It was suggested that the luteal-inducing stimulus is the mechanical stretching of the vagina and/or the cervix which results first from the swelling of the penis and is normally continued by the copulatory plug. Speculation concerning the events occurring during the transport of spermatozoa from the male to the uterus of the female is reported. Possible methods of improving the current techniques of artificial insemination in mice are discussed.
\end{abstract}

\section{INTRODUCTION}

Previous studies (Land \& McGill, 1967; McGill, Corwin \& Harrison, 1968) involved a search for the stimulus provided by the male house mouse during mating that induces formation of functional corpora lutea in the female. The major conclusions of these studies were, first, that the male's pre-ejaculatory, copulatory thrusts are neither necessary nor sufficient for the induction of luteal activity and, second, that the large copulatory plug deposited by the male is not necessary (although it may be sufficient) for the induction of luteal activity in this species. These results narrowed the search for the critical stimulus to events occurring during the ejaculatory reflex of the male.

The behavioural pattern accompanying the ejaculatory reflex in laboratory mice has been described and photographed by Lipkow (1960) and McGill (1962). As a male mouse approaches ejaculation, the tempo of pre-ejaculatory thrusting increases. The male then quivers or shudders strongly while maintaining deep penetration of the female. At this point, he clutches the female with all four limbs and usually falls to his side, frequently carrying the female over with him. He maintains this posture, during which spasms of the scrotum and anal regions may be observed, for 13 to $23 \mathrm{sec}$ depending on genotype (McGill, 1962; McGill \& Blight, 1963).

\footnotetext{
* Present address: Department of Psychology, University of Vermont, Burlington, Vermont, U.S.A.
} 
The present study involved removing the male from the female at various times after the initial ejaculatory shudder and then testing the female to determine if luteal activity had been induced. Observations were also made of the male's penis during the reflex.

\section{MATERIAL AND METHODS}

Subjects in this experiment were of the strain $\mathrm{B}^{2} \mathrm{D}_{2} \mathrm{~F}_{2}$ (the second generation of a cross between inbred C57BL/6J females and inbred DBA/2J males).

The general procedure used in this study was similar to that of the two previous studies in this series (Land \& McGill, 1967; McGill, Corwin \& Harrison, 1968). In brief, sexually experienced males were presented with a succession of females. Matings initiated with a female exhibiting good behavioural oestrus were permitted to continue until the female had received the experimental treatment described below. The females were then caged alone for 48 $\mathrm{hr}$ to ensure that the oestrous phase had passed. At this point, sexually experienced males, called 'indicator males', were introduced into the cages of the females. Females were then examined daily for the presence of copulatory plugs produced by the indicator males, and for the birth of litters. The day of experimental treatment was referred to as Day 0 . Females not affected by the experimental treatment should return to oestrus on Day 4 or Day 5. If experimental treatment produced pseudopregnancy, the female should not return to oestrus until Day 10 to Day 12 (Nalbandov, 1964). Females impregnated during experimental treatment on Day 0 should produce a litter about Day 19.

In the previous experiments of this series, matings were observed while the animals were housed in plastic cylinders 20 in. in height and 10 in. in diameter. In the present experiment, the plastic cylinders were opened to form semicircles. These were securely attached to the breeding tables with the open end toward the experimenter thus allowing ready access to the animals.

An experienced observer can reliably detect the change in tempo of the male's thrusting as ejaculation approaches. This change generally occurs several seconds before the initial ejaculatory shudder. When the experimenter observed that a particular male was about to ejaculate, he grasped the male's tail in one hand and the female's tail in the other. In most cases this caused no interruption of mating. As the ejaculatory shudder occurred, a stopwatch was started by an assistant. The watch was stopped when the experimenter had disengaged the male from the female. Following disengagement, observations were made of the male's penis for several seconds. Next, the female was examined for the presence of a copulatory plug. As mentioned above, females were then isolated for 2 days before the introduction of the indicator males.

\section{RESULTS}

Table 1 presents the results. It shows that when the male was removed within $2 \mathrm{sec}$ of the ejaculatory shudder, fifteen of sixteen females were unaffected by the entire mating, i.e. they returned to oestrus in 4 or 5 days. When the male was removed within 3 or $4 \mathrm{sec}$ most animals exhibited luteal activity; they 
were either pregnant (seventeen females) or pseudopregnant (five females). All females left in contact with the male for 5 or more sec after the beginning of the ejaculatory reflex became pregnant. The results indicate that the critical stimulus for the induction of luteal activity is initiated within 3 or $4 \mathrm{sec}$ of the ejaculatory shudder.

An indication as to the nature of the critical stimulus was obtained by observation of the male's penis during the ejaculatory reflex, i.e. after the male had been removed from the female. (These observations were made on the males used in the study described above and on a larger group of males that mated with females in hormonally induced oestrus.) The observations led to the following general conclusions.

Although the ejaculatory shudder marks the initiation of the ejaculatory reflex, it does not signal the beginning of seminal emission. If a male is removed within 1 or $2 \mathrm{sec}$ after the shudder, the act of ejaculation may be observed. First, the erect penis undergoes a distinct anatomical change. It appears to shorten and definitely becomes much wider particularly at the distal end, where it assumes a cardinal-red colour and a cup-like shape. Approximately 1

TABLE 1

EFFECTS ON FEMALES OF REMOVAL OF MALES AT VARIOUS TIMES AFTER THE EJACULATORY SHUDDER

\begin{tabular}{c|c|c|c}
\hline $\begin{array}{c}\text { Seconds } \\
\text { after } \\
\text { shudder }\end{array}$ & $\begin{array}{c}\text { Females made } \\
\text { pregnant }\end{array}$ & $\begin{array}{c}\text { Females made } \\
\text { pseudopregnant }\end{array}$ & $\begin{array}{c}\text { Females } \\
\text { unaffected }\end{array}$ \\
\hline 1 & & 1 & 11 \\
2 & & 3 & 4 \\
3 & 9 & 2 & 2 \\
4 & 8 & & \\
5 & 3 & & \\
6 & 5 & & \\
7 & 4 & & \\
\hline
\end{tabular}

sec later, the plug is forcibly ejected into this 'penile cup'. Preceding the plug, lying on it but not part of it, is a yellow, sperm-rich fluid. Our observations indicate that the penile cup lasts from 5 to $12 \mathrm{sec}$ during which time strong contractions of the scrotum and anal regions occur, accompanied by pulsations of the penis. Then, the penile cup quickly recedes (usually within $1 \mathrm{sec}$ ). Males removed from 3 to $5 \mathrm{sec}$ after the shudder may leave the entire plug, or part of the plug, in the vagina of the female. The plug might then serve to continue the mechanical stretching initiated by the penile cup.

Plate 1 illustrates some of these events. In Pl. 1, Fig. A the cup has formed and emission of the plug is beginning. Plate 1, Fig. B shows the ejaculated plug in the cup. Plate 1, Fig. C shows the fully formed plug; the penis has retracted from the plug and appears to have returned to the normal erect diameter. The faecal bolus that became accidentally attached to the plug (visible in Figs. B and $C$ ) provides some indication of the relative size of the plug and the organ. 


\section{DISCUSSION}

The results presented in Table 1 , combined with the observations of the changes in the male's penis during the ejaculatory reflex as described above and shown in Plate 1, permit speculation concerning (a) the process of sperm transfer from the male to the uterus of the female and (b) the stimulus necessary for the induction of luteal activity in the female.

In terms of transfer of spermatozoa, the following sequence of events probably occurs. As the ejaculatory reflex begins, the male maintains deep penetration of the female. The penis then assumes the cup-shape which must encompass the entire cervical area of the female. (For the rat, Blandau (1945) speculates that the anatomy of the erect penis serves "to spread the lateral lappets and expose the cervical orifices" while the male's prepuce "... also becomes engorged and encloses the cervical lappets.") Formation of the penile cup is followed by ejaculation, first of the yellow sperm-rich fluid and then of the copulatory plug. The plug is ejected with force and serves to push the spermatozoa through the tightly closed cervix that characterizes oestrus (at least in the rat: Blandau, 1945). When freshly deposited plugs are dissected from females killed for that purpose, one observes that the plug has penetrated deeply into the cervix. At times, strands of plug material extend completely through the cervix and into the uterus. The hypothesis that the function of the copulatory plug in the mouse is to force spermatozoa through the cervix into the uterus and/or to aid in holding spermatozoa in the uterus was previously stated (McGill et al., 1968). To this, we may add the hypothesis that the plug also functions to continue the vaginal/cervical stretching initiated by the penile cup. However, the fact that the plug is not necessary for the induction of luteal activity should be kept in mind.

It is interesting to note that the delay between the initial ejaculatory shudder and seminal emission in the mouse has a distinct parallel in the human male. "Contraction of the secondary organs of reproduction is experienced in the male as an anticipatory sign of imminent ejaculation. The sensation develops over a 2- to 3-sec time interval, and has been described by many males as a feeling that ejaculation is coming, and that it can no longer be voluntarily controlled. This anticipatory sensation coincides with the actual internal ejaculation of seminal plasma into the prostatic urethra" (Masters \& Johnson, 1965).

A question arises as to how closely our observations coincide with occurrences within the female's vagina when the pair is not separated. It seems reasonable to assume that the penis retains its cup-shape for a longer time within the vagina. This would be accompanied by a longer 'pumping' action on the part of the male and increase the probability of forcing spermatozoa through the cervix.

The purpose of this study was to determine what aspect of the ejaculatory reflex in the male mouse triggers the neuro-endocrinological reflex that results in functional corpora lutea in the female. It is possible to postulate a mechanical trigger (the increase in size of the penis and/or stimulation by the papillae visible in Plate 1), a thermal trigger (the cardinal-red colour might be accompanied by an increase in the temperature of the penis), and a chemical trigger (some component of the semen). Since the mechanical trigger hypothesis 


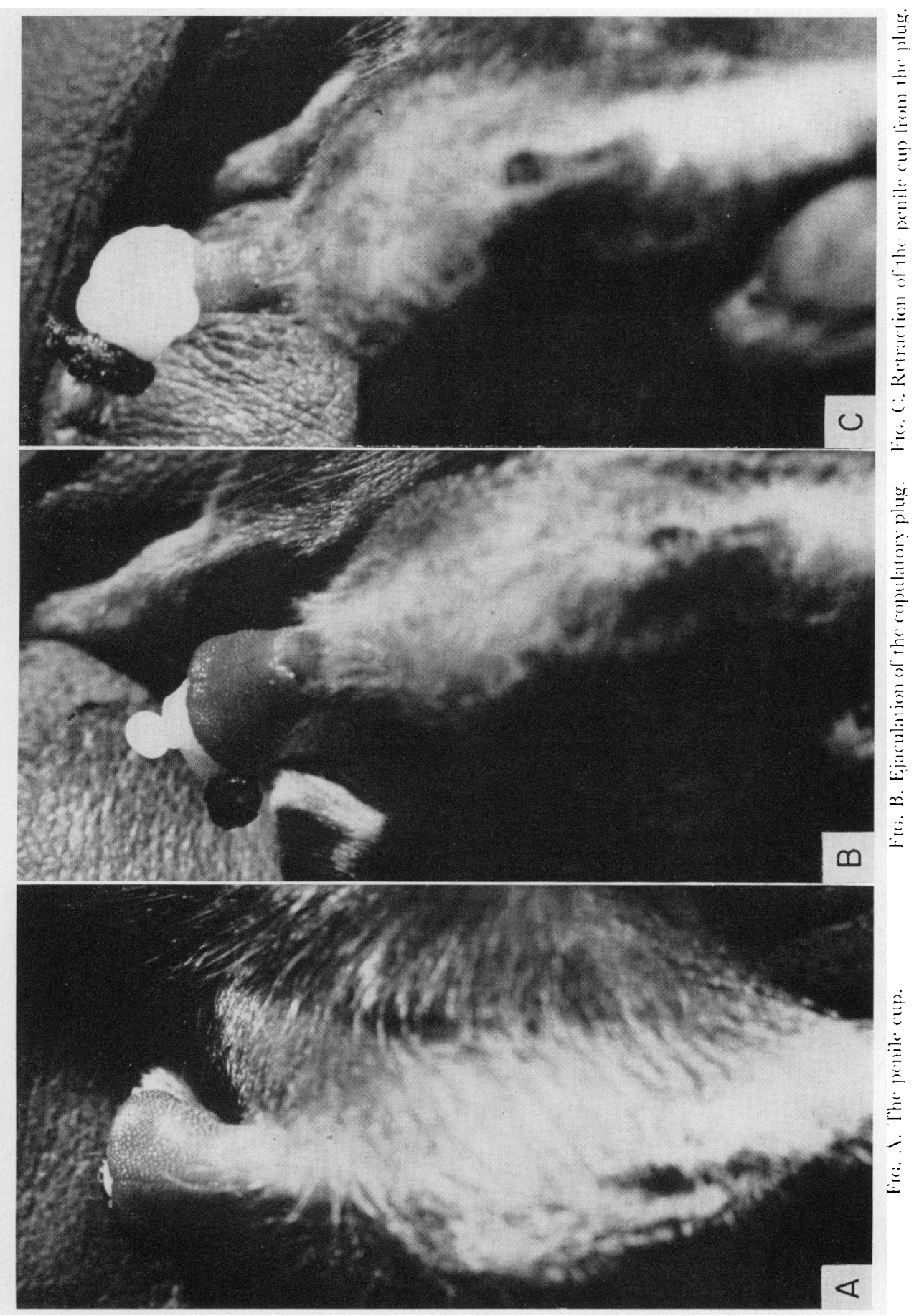


appears most likely to us, experiments designed artificially to induce luteal activity in oestrous female mice by mechanical means are currently in progress in this laboratory.

Our studies may also have certain practical applications in terms of improving techniques of artificial insemination in mice. Current methods involve killing of the donor male followed by stripping of spermatozoa from the vas deferens. Our experiments indicate that, when the donor male can be induced to copulate, spermatozoa can be collected more easily, in greater quantities, and (perhaps more important) repeatedly, by the method of removing the male from a female just after the ejaculatory shudder. Furthermore, if our experiments involving induction of luteal activity in the female by means of an artificial penis are successful, it will no longer be necessary to mate the female with a vasectomized male to induce luteal activity following the injection of spermatozoa into the uterus.

An alternative to the technique of stripping spermatozoa from the vas deferens involves the induction of ejaculation by electrical stimulation through the spinal cord. We have replicated this technique with several different males and have succeeded in securing small plugs and some spermatozoa. However, in no instance was either the quantity of spermatozoa, or the size of the plug ejaculated, equal to that obtained when the male is removed from the female as described above. Furthermore, in no instance was the dramatic change in penis structure observed. This observation suggests that the complete ejaculatory reflex involves supra-spinal neural centres as well as spinal reflex mechanisms. If this is true, then studies involving penile reflexes in spinal animals (Hart, 1967, 1968) should be interpreted with caution since the response that occurs in the intact animal (normally hidden from the observer since it occurs within the vagina of the female) may be quite different from that seen in the spinal preparation.

Note added in proof: Since this was written, one of us (T.E.M.) has spoken with Dr Hart who reported that some of the reflexes he has observed in the spinal rat are similar to the penile cup described in the present paper. This observation indicates that the reflex may not involve supra-spinal centres, except as these normally function to inhibit the reflex. Disinhibition apparently does not occur during ejaculation induced by electrical stimulation of the spinal cord in the intact animal.

\section{ACKNOWLEDGMENTS}

This research was supported in part by Research Grant GM-07495 from the Institute of General Medical Sciences, U.S. Public Health Service. The second author was an NSF trainee in the Undergraduate Science Education Program; NSF Grant No. GY 872.

\section{REFERENCES}

BLANDAU, R. J. (1945) On the factors involved in sperm transport through the cervix uteri of the albino rat. Am. F. Anat. 77, 253.

HART, B. L. (1967) Testosterone regulation of sexual reflexes in male rats. Science, N.Y. 155, 1283.

HART, B. L. (1968) Sexual reflexes and mating behavior in the male rat. F. comp. physiol. Psychol. 65, 453. 
LAND, R. B. \& McGill, T. E. (1967) The effects of the mating pattern of the mouse on the formation of corpora lutea. F. Reprod. Fert. 13, 121.

Lipkow, J. (1960) Die Begattung bei der weissen Maus. Z. Tierpsychol. 17, 182.

MaGilı, T. E. (1962) Sexual behavior in three inbred strains of mice. Behaviour, 19, 341.

MaGill, T. E. \& Blight, W. C. (1963) The sexual behaviour of hybrid male mice compared with the sexual behaviour of males of the inbred parent strains. Anim. Behav. 11, 480.

MaGill, T. E., Corwin, D. M. \& Harrison, D. T. (1968) Copulatory plug does not induce luteal activity in the mouse Mus musculus. F. Reprod. Fert. 15, 149.

Masters, W. H. \& Johnson, V. E. (1965) The sexual response cycles of the human male and female: Comparative anatomy and physiology. In: Sex and Behavior, p. 525. Ed. F. A. Beach. Wiley, New York.

Nalbandov, A. V. (1964) Reproductive physiology, 2nd edn, p. 258. Freeman, San Francisco. 